\title{
ANALYSIS OF AN EXTREME LOSS OF COOLANT IN THE IPR-R1 TRIGA REACTOR USING A RELAP5 MODEL
}

\author{
P. A. L. Reis ${ }^{\mathrm{a}}$, \\ A. L. Costa ${ }^{a}$, \\ C. Pereira ${ }^{a}$, \\ M. A. F. Veloso ${ }^{\mathrm{a}}$, \\ H. V. Soares ${ }^{\mathrm{a}}$, \\ and A. Z. Mesquitab \\ ${ }^{a}$ Departamento de Engenharia Nuclear, \\ Universidade Federal de Minas Gerais, \\ Av. Antônio Carlos, 6627, Campus UFMG, \\ Escola de Engenharia, \\ CEP. 31270-901, Belo Horizonte, Brasil \\ patricalire@yahoo.com.br \\ ${ }^{\mathrm{b}}$ Centro de Desenvolvimento da Tecnologia \\ Nuclear/Comissão Nacional de Energia Nuclear - \\ CDTN/CNEN, Av. Antônio Carlos, 6627, \\ Campus UFMG, Belo Horizonte, Brasil \\ Received: October 25, 2013 \\ Revised: November 14, 2013 \\ Accepted: December 30, 2013
}

\section{INTRODUCTION}

Several transient events are possible to occur in research reactors, as for example, loss of electrical power supplies, insertion of excess reactivity, loss of flow, loss of coolant, erroneous handling or failure of equipment or components, special internal events, external events and human errors (IAEA, 2005).

The main activity of a nuclear research reactor is not for energy generation reaching maximum power operation of about $100 \mathrm{MW}$. In spite of this, specific features are necessary to ensure safe utilization of such installations. Therefore, several codes such as, for example, RELAP5, RETRAN, CATHARE, ATHLET and COBRA have been used focusing special attention for research reactors safety analysis and valuation of specific perturbation plant licensing and operation of research reactors.

RELAP5 code (US NRC, 2001) was used in this work to perform steady state and transient simulations of the IPR-R1 TRIGA research reactor. The RELAP5 system code was developed to simulate transient scenarios in power reactors. However, recent works have been performed to investigate the applicability of such code to research reactor

\section{ABSTRACT}

The RELAP5/MOD3.3 code has been applied for thermal hydraulic analysis of power reactors as well as nuclear research reactors with good predictions. The development and the assessment of a RELAP5 model for the IPR-R1 TRIGA have been validated for steady state and transient situations. The reactor is located at the Nuclear Technology Development Centre (CDTN), Brazil. It is a $250 \mathrm{~kW}$, light water moderated and cooled, graphite-reflected, open pool type research reactor. In this work, an extreme transient case of loss of coolant accident (LOCA) has been simulated. For this type of analysis, the automatic scram of the reactor was not considered because the main aim was to verify the evolution of the fuel elements heating in the absence of coolant. The temperature evolutions are presented as well as an analysis about the temperature safety limits.

Keywords: RELAP5, TRIGA IPR-R1, LOCA

operation conditions.

In spite of the IPR-R1 to be inherently safe, situations that can disturb the normal reactor operation are possible to occur. The RELAP5 model presented in this work has demonstrated to reproduce very well the steady state conditions. Therefore, a hypothetical loss of coolant accident (LOCA) was investigated using the model developed.

Particularly, in this work an extreme case of LOCA was investigated. During the LOCA event, the internal natural circulation of the fluid is suppressed and an excessive core heat-up is expected to occur (Hamidouche and Si-Ahmed, 2011). The probability of this kind of accident in the IPR-R1 is much reduced according to design and safety features. However, the recent event occurred at Fukushima in 2011, demonstrated that all possibilities of accident must be considered (D'Auria et al., 2012). In the IPRR1, the LOCA accident would occur due to a drastic crack in the pool bottom.

For the LOCA simulation the automatic scram was not considered to allow the verification of the temperature evolutions after total loss of the coolant. The IPR-R1 fuel is an Uranium and Zirconium Hydride alloy. In TRIGA type reactors the fuel temperature limit is related to the dehidrogenation of 
the fuel and consequent tension in the cladding of the fuel. For the mixture of U-ZrH1.0 fuel with aluminum cladding $1100-\mathrm{F}$ type, the maximum temperature of the fuel is fixed by General Atomic as 1173 K (Gulf General Atomic, 1970), assuring that the tension in the cladding due the hydrogen pressure will be lower than the limit supported by it at $743 \mathrm{~K}$ of temperature. For the reactor operation, the fuel temperature limit is maintained at about $820 \mathrm{~K}$ that is the temperature for which phase change of U-ZrH1.0 fuel is observed (Veloso, 2005).

\section{IPR-R1 - GENERAL DESCRIPTIONS}

The IPR-R1 is a reactor type TRIGA (Training, Research, Isotope, General Atomic), Mark-I model, manufactured by the General Atomic Company and installed at Nuclear Technology Development Centre (CDTN) of Brazilian Nuclear Energy Commission (CNEN), in Belo Horizonte, Brazil. The reactor is housed in a 6.625 meters deep pool with 1.92 meters of internal diameter and filled with demineralized light water.

The water in the pool has function of cooling, moderator and neutron reflector and it is also able to assure an adequate radioactive shielding. The reactor cooling occurs predominantly by natural convection, with the circulation forces governed by the water density differences. To perform the heat removal generated in the core, the water of the pool is pumped through a heat exchanger. The core has a radial cylindrical configuration with six concentric rings (A, B, C, D, E, F) with 91 channels able to host either fuel rods or other components like control rods, reflectors and irradiator channels. There are 63 fuel elements constituted by a cylindrical metal cladding filled with a homogeneous mixture of zirconium hydride and Uranium $20 \%$ enriched in ${ }^{235} \mathrm{U}$ isotope.

There are 59 fuel elements covered with aluminum and 4 fuel elements with stainless steel. The main thermal-hydraulic and kinetic characteristics of the IPR-R1 core are listed in (Reis et al., 2010).

The radial relative power distribution (Fig. 1) was calculated in preceding works using the WIMSD4C and CITATION codes and also experimental data (Dalle et al., 2002). The radial factor is defined as the ratio of the average linear power density in the element to the average linear power density in the core. In the Fig. 1 is also possible to see the six core concentric rings (A, B, C, D, E, F).

\section{NODALIZATION}

A schematic reactor diagram is illustrated in the Figure 2 (first picture). The IPR-R1 nodalization, based in such diagram, is represented in a general way in the Figure 2 (second picture). The reactor pool was modeled using two pipe components, each one composed by ten volumes. The volumes of each pipe of the pool are equivalently connected between them by single junctions (SJ) characterizing a pool crossflow model. A time dependent volume (TDV) was used to simulate the atmospheric pressure on the pool surface (identifier 500). The natural convection system and the primary loop circulation have been modeled. The secondary loop, composed mainly by the external cooling tower was not modeled in the present nodalization because the primary circuit was sufficient to guaranty the heat removal of the coolant.

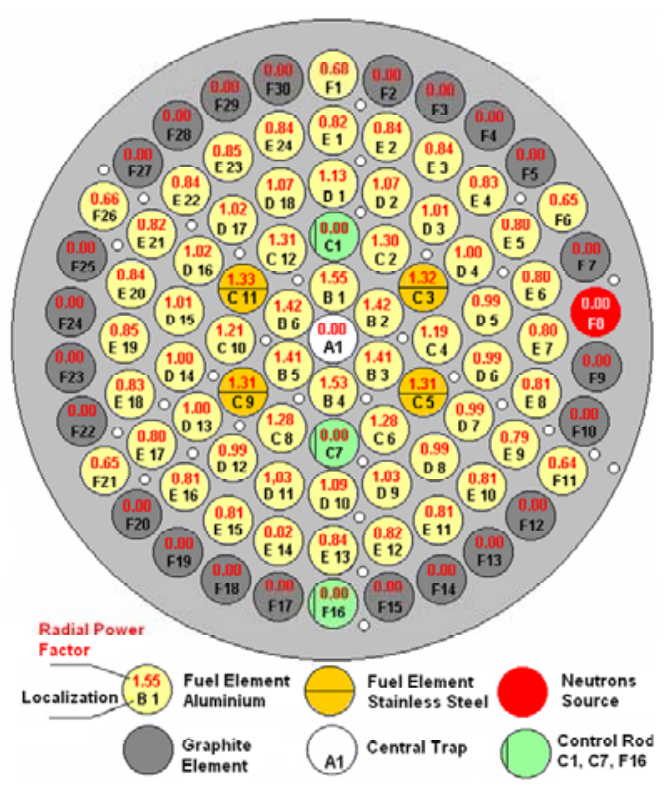

Figure 1. IPR-R1 reactor - radial relative power distribution (Veloso, 2005).

To simulate the forced circulation, the pipe 132 was connected in the first volume of the pool using the single junction 131 . The water returns to the pool coming into the volume 6 through the pipe 330. The pump 300 supplies the water circulation. In the nodalization the valve 325 is normally closed. It opens to simulate the LOCA transient forcing the cooling to follow to the TDV 327.

In the nodalization, each of the 63 fuel elements and others like the regulation and control rods, the reflector elements and the neutron source were modeled separately and were associated with 03 corresponding hydrodynamic pipe components constituting 03 hydrodynamic channels as it can be verified in the Fig. 3 (axial view) and Fig. 4 (radial view).

The point kinetics model was used in the current simulations. A detailed representation of each element is, however, essential to properly take into account the radial power distribution associated with the position of the fuel elements. The axial power distribution was calculated considering a cosine profile and taking into account also that the power is cut off in the extremes of the element due the 
presence of the graphite. Although the above modeling procedure is approximated, it is used here to conserve the actual axial and radial power distribution fixed.

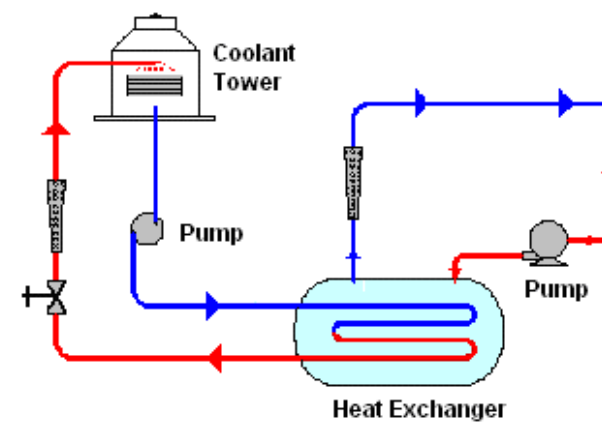

Secundary Loop Primary Loop
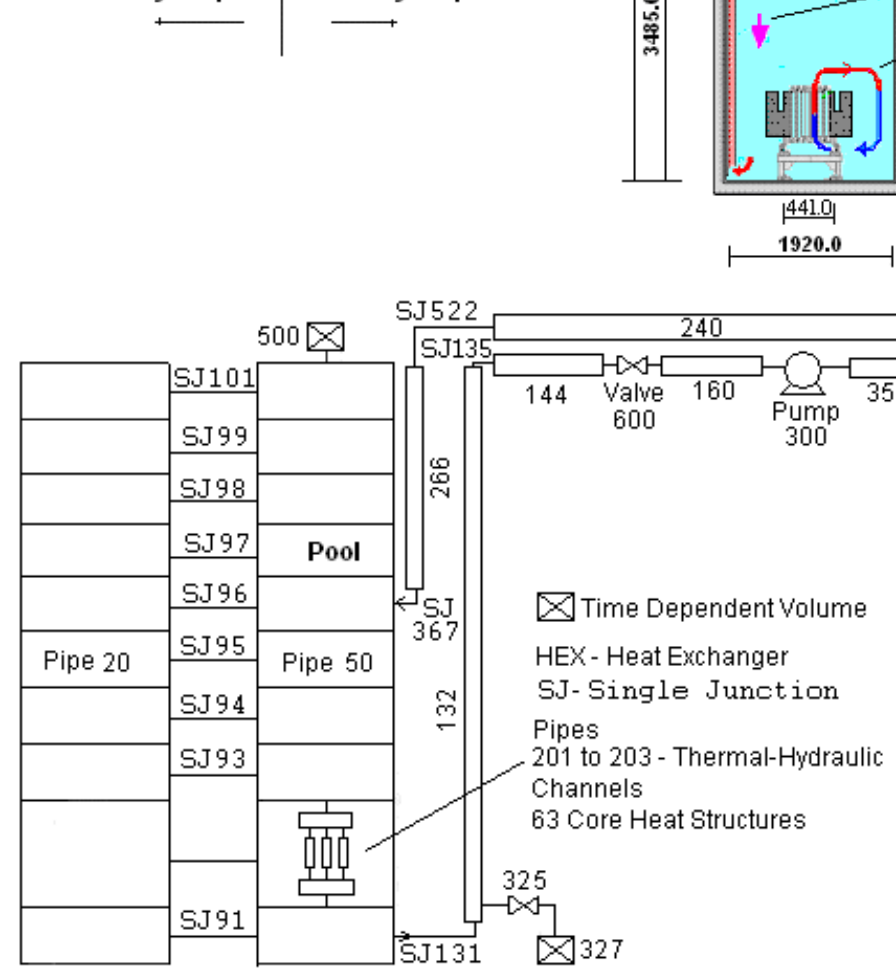

Figure 2. IPR-R1 - first picture: Schematic representation of the IPR-R1 (out of scale, measure in mm) (Mesquita, 2005); second picture: nodalization in the RELAP5.

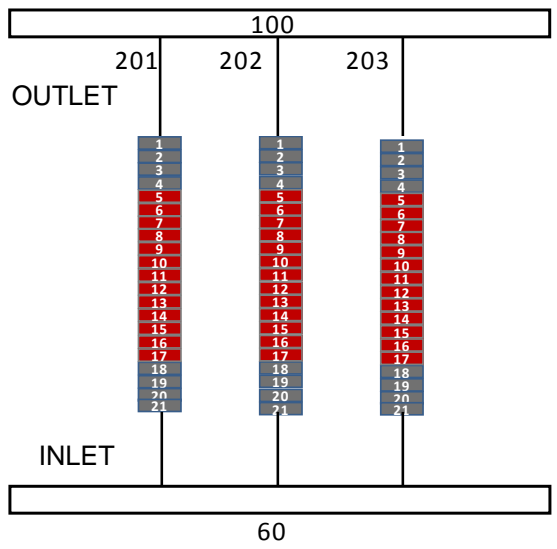

Figure 3. Core nodalization: axial view.

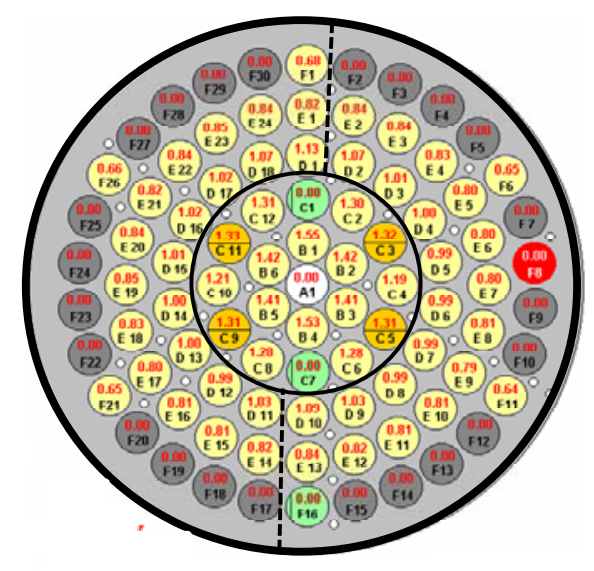

Figure 4. Core nodalization: radial view. 


\section{RESULTS AND ANALYSES}

\section{Steady State Results}

The validation of a RELAP5 nodalization implicates that the model reproduces the measured steady state conditions of the system with acceptable margins. The nodalization may be considered qualified when it has a geometric fidelity with the system, it reproduces the measured steady-state condition of the system, and it demonstrates satisfactory time evolution conditions.

The RELAP5 steady-state calculation has been performed for the IPR-R1 operating at $100 \mathrm{~kW}$. The point kinetics model was used in the simulations. The axial power distribution was calculated considering a cosine profile. The temperature values at the inlet and outlet core TH channels were calculated and compared with the calculated data provided in a previous work (Reis et al., 2012) with good results validating the model. Figure 5 shows the inlet and outlet coolant temperature evolution for the hottest channel (201). As it can be verified, the steady state is reached at about 2,500 s of calculation. There is an increase of the coolant temperature of approximately $5 \mathrm{~K}$ after to cross the core.

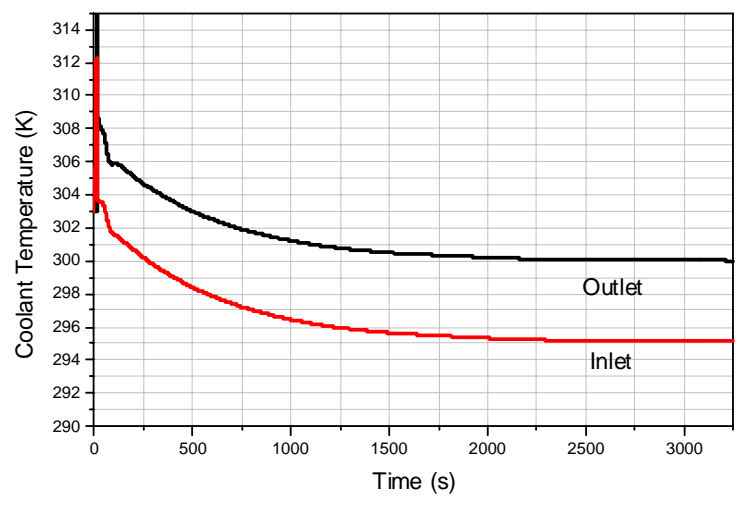

Figure 5. Inlet and outlet core coolant temperature time evolution.

\section{LOCA Simulation}

LOCA can be a consequence of the following events: rupture of the primary coolant boundary, damaged pool, pump-down of the pool, failure of beam tubes or other penetrations. Therefore, LOCA considering pool damage was investigated in this work using the RELAP5 model for the IPR-R1.

After the calculation to reach steady-state behavior at $100 \mathrm{~kW}$ of power operation, the transient started. To perform the simulation, the valve 325 (see Figure 2 - second picture) connected in the pipe 132 in the nodalizaton was opened at $4,000 \mathrm{~s}$ of calculation. The water in the pool began to decrease immediately. The coolant was forced to coming into the TDV 327 that is at atmospheric pressure. As it can be verified in the Figure 6, after about $150 \mathrm{~s}$ from the start of the transient, practically all pool coolant is lost. Figure 7 shows the void fraction evolution at core inlet and outlet. After about 4,200 s of calculation, the core is totally uncovered (void fraction reaches approximately 100\%). The value of the pressure in bottom of the pool dropped reaching atmospheric level (Figure 8) as it was expected.

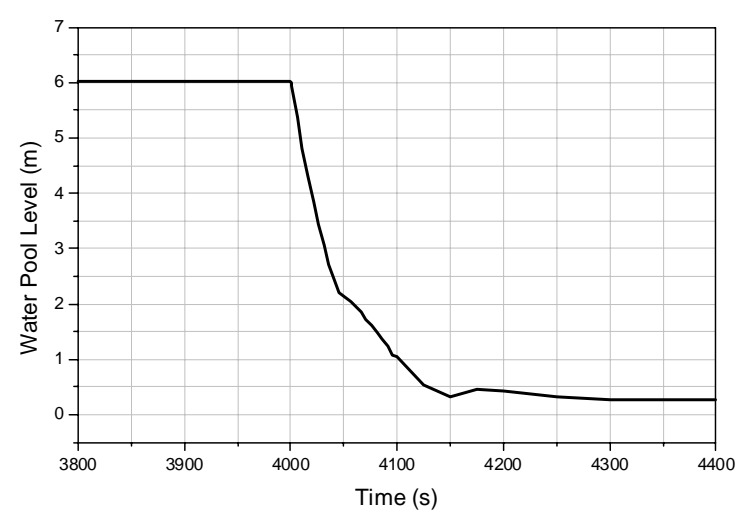

Figure 6. Transient evolution: water pool level.

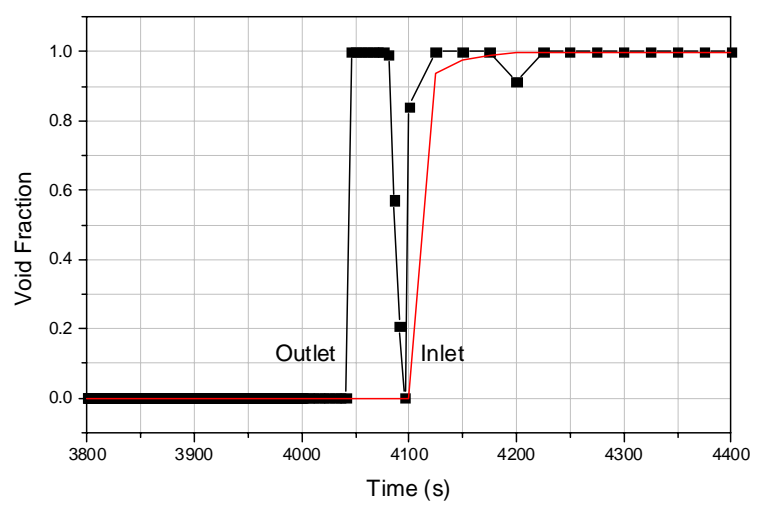

Figure 7. Transient evolution: core inlet and outlet void fraction.

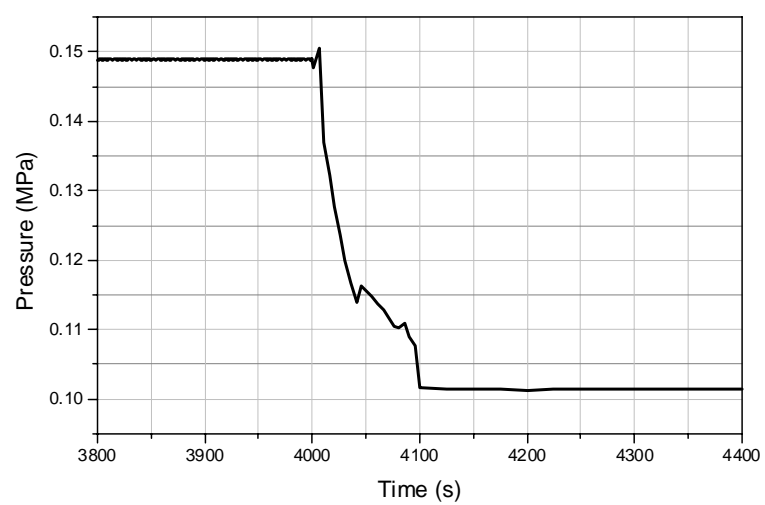

Figure 8. Transient evolution: the bottom pool pressure. 
Figure 9 illustrates fuel and cladding temperatures time evolution at the middle of element B2 (see Figure 4). After about 4,200 s, the core is totally uncovered and, consequently, the heat generated by the fuel is no more removed by convection being then realized only by radiation. As it can be verified in the Fig. 9, the fuel and cladding temperatures increase drastically beyond the project limits.

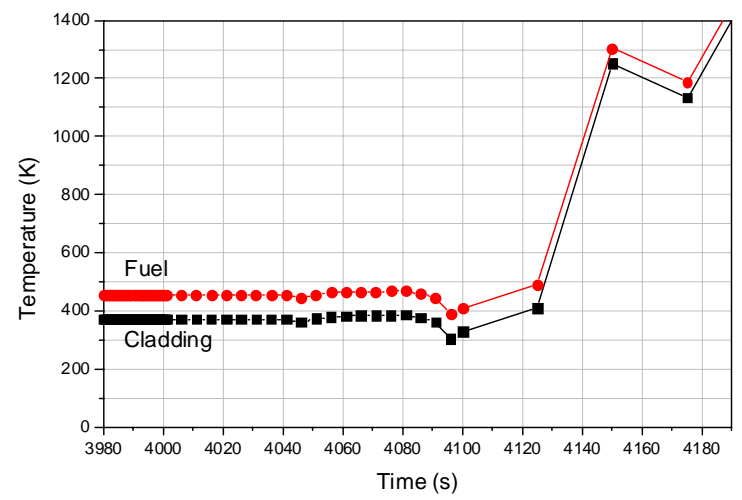

Figure 9. Cladding and fuel time evolution temperatures in the middle of a central fuel element.

\section{CONCLUSIONS}

LOCA event is a consequence of one of the following events: rupture of the primary coolant boundary, damaged pool, pump-down of the pool, failure of beam tubes or other penetrations. Therefore, LOCA considering pool damage was investigated in this work. The simulation of an extreme LOCA in the IPR-R1 reactor was considered using a validated RELAP5 model. As the automatic scram was not considered, the temperatures of the fuel and cladding exceeded the safety limits in few minutes as it was expected. Further studies will be performed to investigate in more details this type of event and the ways to mitigate its deleterious effects.

The results of the thermal-hydraulic parameters time evolution before and after the accident, demonstrated the expected behaviors. As no one safety intervention was considered after the beginning of the transient, the temperatures increase drastically and the limits were exceeded.

Moreover, as the simulation considers only point kinetics neutronic calculation, negative insertion reactivity due to the intrinsic characteristics of the TRIGA fuel was not considered in the results. In TRIGA reactors, an important characteristic for the control of the core reactivity is its large prompt negative fuel temperature coefficient. Therefore, a future activity is to couple thermal-hydraulic and neutron kinetic calculation to reach more realistic predictions.

\section{ACKNOWLEDGEMENTS}

The authors are grateful to FAPEMIG, CDTN/CNEN, CNPq and CAPES for the support.

\section{REFERENCES}

Dalle, H. M., Pereira, C., and Souza, R. M. G. P., 2002, Neutronic Calculation to the TRIGA IPRR1 Reactor using the WIMSD4 and CITATION Codes, Annals of Nuclear Energy, Vol. 29, pp. 901912.

D’Auria, F., Galassi, G., Pla, P., and Adorni, M., 2012, The Fukushima Event: the Outline and the Technological Background, Science and Technology of Nuclear Installations, pp. 1-25.

Gulf General Atomic, 1970, Safeguards Summary Report for the New York University TRIGA Mark I Reactor, Gulf General Atomic, San Diego, CA, GA-9864.

Hamidouche, T., and Si-Ahmed, El-K., 2011, Analysis of Loss of Coolant Accident in MTR pool type Research Reactor, Progress in Nuclear Energy, Vol. 53, pp. 285-289.

IAEA, 2005, Safety of Research Reactors. IAEA Safety Standards Series, No. NS-R-4, IAEA, Vienna.

Mesquita, A. Z., 2005, Investigação Experimental de Temperatura no Reator Nuclear de Pesquisa TRIGA IPR-R1, Doctoral Thesis, Faculdade de Engenharia Química, Universidade de Campinas, Campinas, SP. (in Portuguese)

Reis, P. A. L., Costa, A. L., Pereira, C., Veloso, M. A. F., Mesquita, A. Z., Soares, H. V., and Barros, G. P., 2010, Assessment of a RELAP5 model for the IPR-R1 TRIGA Research Reactor, Annals of Nuclear Energy, Vol. 37, pp. 1341-1350.

Reis, P. A. L., Costa, A. L., Pereira, C., Silva, C. A. M., Veloso, M. A. F., and Mesquita, A. Z., 2012, Sensitivity Analysis to a REAP5 Nodalization Developed for a Typical TRIGA Research Reactor, Nuclear Engineering and Design, Vol. 242, pp. 300306.

US NRC, 2001, RELAP5/Mod3.3 Code Manuals, Idaho National Engineering Laboratory.

Veloso, M. A., 2005, Avaliação TermoHidráulica do Reator TRIGA IPR-R1 a $250 \mathrm{~kW}$, CDTN/CNEN, Nota Interna NI-EC3-05/05. (in Portuguese) 